Check for updates

Cite this: RSC Adv., 2018, 8, 6840

Received 13th January 2018 Accepted 2nd February 2018

DOI: $10.1039 / \mathrm{c} 8 \mathrm{ra00392k}$

rsc.li/rsc-advances

\title{
Efficient removal of pentachlorophenol from aqueous solution by 4-tert-butylcalix[8]arene modified thermally sensitive hydrogels
}

\author{
Ying Guo, ${ }^{\text {ab }}$ Bing Liao, ${ }^{c}$ Kun Wang, ${ }^{\text {ab }}$ Yangyang Zhao, ${ }^{\text {ab }}$ Qiwen Yong, ${ }^{\text {ab }}$ \\ Hongwei Zhao ${ }^{\mathrm{ab}}$ and Hao Pang (iD *a
}

\begin{abstract}
We prepared poly(N-isopropylacrylamide-co-4-tert-butylcalix[8]arene) (PNIPAM-TBCX) hydrogels by copolymerization of $\mathrm{N}$-isopropylacrylamide (NIPAM) with 4-tert-butylcalix[8]arene (TBCX) to capture hazardous pentachlorophenol (PCP) from aqueous solution. Adsorption experiments showed that the adsorption capacities of PNIPAM-TBCX hydrogels reached 1.96, 2.08 and $2.02 \mathrm{mg}$ PCP per $1 \mathrm{~g}$ of hydrogel, while the molar percentage ratio of TBCX in the hydrogels was as low as $0.5 \%, 0.7 \%$ and $1 \%$. The equilibrium adsorption of PCP on the hydrogels was studied using different adsorption models. In addition, the PNIPAM-TBCX hydrogel still retained its performance when regenerated several times by immersing in water at $323 \mathrm{~K}$.
\end{abstract}

\section{Introduction}

Pentachlorophenol (PCP) is a widely distributed pollutant. It was commonly used as a wood preservative and it is hard to degrade, meanwhile it could be derived from atmospheric oxidation of a highly persistent, globally distributed organic pollutant, hexachlorobenzene. ${ }^{1}$ Long-term exposure to PCP, even at low levels, can cause serious damage to the liver, kidneys, blood, reproductive organs and nervous system. ${ }^{2}$ PCP is a hydrophobic ionizable organic compound due to its high octanol-water partition coefficient $\left(\log k_{\mathrm{ow}}=5.25\right)$ and low $\mathrm{p} K_{\mathrm{a}}$ value (4.5). ${ }^{3}$ It exists in the presence of both ionic and molecular species in aqueous solution.

Various biological, chemical and physical techniques have been developed to remove PCP, such as microbe degradation, ${ }^{4}$ biological $^{5}$ and synthetic ${ }^{3}$ enzyme catalysis, photocatalytic oxidation, ${ }^{6}$ electrochemical processes, ${ }^{7}$ dechlorination with $\mathrm{Fe} /$ Ni nanomaterials, ${ }^{8}$ and adsorption strategies. Because of its facile operation and high efficiency, the adsorption method attracts the attention of many researchers. The adsorption would take place if the kinetic energy of adsorbate is not sufficient to overcome the potential barrier of the residual free force field on the adsorbent surface. Thus, high special surface area is essential to adsorb PCP. Several types of materials have been used as adsorbents, such as natural products (eggshells, ${ }^{9}$ corn wastes, ${ }^{10}$ biochar $^{\mathbf{1 1}}$ and so forth), boron nitride ${ }^{\mathbf{1 2}}$ and carbon

${ }^{a}$ Key Laboratory of Cellulose and Lignocellulosics Chemistry, Guangzhou Institute of Chemistry, Chinese Academy of Sciences, Guangzhou 510650, People's Republic of China. E-mail: panghao@gic.ac.cn

${ }^{b}$ University of Chinese Academy of Sciences, Beijing 100049, People's Republic of China ${ }^{c}$ Guangdong Academy of Sciences, Guangzhou 510650, Republic of China nanotubes, ${ }^{13}$ cobalt ferrite ${ }^{\mathbf{1 4}}$ and alumina $^{15}$ nanoparticles, chitin $^{16}$ and hydrogels. ${ }^{17}$ Among these multifarious adsorption materials, smart hydrogel is unique in that it can be easily regenerated. The high swelling ratio and specific surface area, connected porous structure,$^{\mathbf{1 8}}$ thermo-sensitive property ${ }^{\mathbf{1 9}}$ and feasible modification ${ }^{20}$ made the PNIPAM hydrogel widely used in adsorption ${ }^{21}$ and drug delivery. ${ }^{22}$

The calixarene $(\mathrm{CX})^{23}$ is a macrocyclic cavitand compound with two portals that can form complexes with small ions and organic molecules by hydrogen bonding, van der Waals' force, hydrophobic interactions or shape complementation. Therefore, the $\mathrm{CX}$ and its derivatives show high supramolecular recognition and enrichment capabilities with organic molecules and ions. ${ }^{24}$ By combining the merits of $p$-sulfonated calix [8] arene and the single-walled carbon nanohorns, a highly sensitive dual-signalling electrochemical sensing platform for a organic molecule aconitine has been developed. ${ }^{25}$ Based on the conformation of calix[4]arene bearing diverse tails, a novel fluorometric chemosensor displaying selective response toward $\mathrm{Ag}^{+}$among different metal ions ${ }^{26}$ and a calix-conjugated thermo-responsive hydrogel used to remove nickel(II) from its aqueous solution ${ }^{27}$ have been prepared. When PCP dissolved in neutral ionized water, at low concentrations from $6 \mathrm{mg} \mathrm{L}^{-1}$ to $20 \mathrm{mg} \mathrm{L}^{-1}$, the ratio of molecular and ionized PCP species ranges from 0.84 to 1.54 , and the $\mathrm{pH}$ value of PCP aqueous solution is from 4.57 to 4.31 . The ratio of molecular and ionized PCP species increases with the decreasing of $\mathrm{pH}$ value for PCP aqueous solution. The poly( $N$-isopropylacrylamide) (PNIPAM) hydrogel absorbs more the molecular than the ionized PCP species due to hydrophobic interaction. Thus, the poly $(N$-isopropylacrylamide) (PNIPAM) hydrogel was hydrophobically modified to enhance the adsorption for PCP under the 
condition of the $\mathrm{pH}$ value of 3 in the published literature. ${ }^{17}$ The above mentioned method complicated the purification of sewage and caused a secondary pollution. The others reported that some adsorbents could be used to remove PCP from aqueous solution without adjusting $\mathrm{pH}$ value, but difficult to recycle. ${ }^{9,28}$ Taking into account that PCP exists in the presence of ionic and molecular species in aqueous solution and CX can bind different polar substances, we synthesized a novel thermosensitive hydrogel (PNIPAM-TBCX). The PNIPAM-TBCX hydrogel was comprised of NIPAM and 4-tert-butylcalix[8]arene, and the calixarene with rigid benzene ring was proposed to increase the porous size and surface area of the hydrogel and to enhance the interaction between the hydrogel and PCP. In addition, the thermo-sensitive PNIPAM-TBCX hydrogel could be simply regenerated by immersing it in the water at temperature higher than its lower critical solution temperature.

In this study, we have synthesized the PNIPAM-TBCX hydrogels with different 4-tert-butylcalix[8]arene contents. The adsorption kinetics of PCP on the hydrogels and the reusability of the hydrogels were investigated. We also discussed the interactions between the hydrogels and PCP to reveal the adsorption mechanism.

\section{Experimental}

\subsection{Materials}

All experiments were performed with deionized water at a neutral pH. N-Isopropylacrylamide (NIPAM) (98\%, Aladdin Co., Ltd, Shanghai, China) was purified via recrystallization from $n$-hexane and dried under vacuum at room temperature. $p$-tert-Butylphenol, $N, N^{\prime}$-methylenebis(acrylamide) (BIS), $N, N, N^{\prime}, N^{\prime}$-tetramethylenediamine (TEMED), ammonium persulfate (APS), sodium dodecyl sulfate, sodium hydroxide, triethylamine, 4-pentenoyl chloride were all of analytical grade, and used without further purification.

\subsection{Experiments}

2.2.1 Synthesis of 4-tert-butylcalix[8] arene. We synthesized 4-tert-butylcalix[8]arene (Fig. 1) according to the literature procedure. ${ }^{29}$ A slurry prepared from $50 \mathrm{~g}$ (ca. $0.33 \mathrm{~mol}$ ) of $p$-tertbutylphenol, $17.5 \mathrm{~g}$ ( $\mathrm{ca} .0 .55 \mathrm{~mol}$ ) of paraformaldehyde, and $1.0 \mathrm{~mL}(0.01 \mathrm{~mol})$ of $10 \mathrm{~mol} \mathrm{~L}^{-1}$ sodium hydroxide in $300 \mathrm{~mL}$ of $o$-xylene were placed in a $1 \mathrm{~L}$, round-bottomed, three-necked flask fitted with a Dean-Stark water collector and a magnetic stirrer. The air in the flask was replaced with nitrogen. The reaction mixture was heated to reflux over $2 \mathrm{~h}$ and kept reflux for $4 \mathrm{~h}$. Then the mixture was placed to cool down to room temperature, and was filtrated to collect precipitate. The crude product was washed, successively, with $400 \mathrm{~mL}$ portions of toluene, ether, acetone and water, then dried under reduced pressure. It was subsequently dissolved in ca. $800 \mathrm{~mL}$ of boiling chloroform. The chloroform solution was concentrated to $c a$. $600 \mathrm{~mL}$ and cooled to room temperature. The precipitate was collected by filtration to yield a colorless powder.
2.2.2 Synthesis of $O(1)-(4-p e n t e n o y l)-p$-tert-butylcalix[8] arene. Referring to the dual acylation method of 1,1'-bi-2naphthol ${ }^{30}$ and the single acylation method of 1,3-dihydroxybenzene, ${ }^{31}$ we synthesized $O(1)$-(4-pentenoyl)-p-tert-butylcalix [8]arene (Fig. 1). A suspension of $1.30 \mathrm{~g}$ (ca. $1.0 \mathrm{mmol}$ ) 4-tertbutylcalix[8]arene and $1.05 \mathrm{~g}$ (ca. $1.01 \mathrm{mmol})$ triethylamine in $15 \mathrm{~mL}$ of trichloromethane was cooled to $273 \mathrm{~K}$. Over a period of $20 \mathrm{~min}$, a solution of $1.19 \mathrm{~g}(1.0 \mathrm{mmol})$ of 4-pentenoyl chloride in $10 \mathrm{~mL}$ trichloromethane was added. Then the mixture was warmed to room temperature naturally and stirred for two additional hours to ensure complete reaction. The filtrate was obtained by pumping filtration, and washed with $\mathrm{HCl}$ aq. (5 wt\%), $\mathrm{NaOH}$ aq. (5 wt\%) and water, resulting in an almost colorless trichloromethane solution. This trichloromethane solution was dried over magnesium sulfate, filtered and concentrated by rotary evaporation to yield skin-pink solid.

2.2.3 Synthesis of the PNIPAM-TBCX hydrogels. Poly $(N$ isopropylacrylamide-co-4-tert-butylcalix[8] arene) (PNIPAMTBCX) hydrogels (Fig. 1) were synthesized via aqueous micellar polymerization. A fixed molar ratio of NIPAM $(0.5 \mathrm{~g})$ and BIS (10:1) were dissolved in $4.5 \mathrm{~g}$ deionized water, and then different amounts of $O(1)$-(4-pentenoyl)-p-tert-butylcalix[8] arene $(0.5-1 \mathrm{~mol} \%$ of NIPAM) were added into the mixture. The solution was degassed by bubbling nitrogen for $20 \mathrm{~min}$. Then, sodium dodecyl sulfate (SDS, 35 mass times of $O(1)$-(4-pentenoyl)-p-tert-butylcalix[8]arene) was added, and the hydrophobic monomers were solubilized within the surfactant micelles. After adding APS and TEMED as a redox initiator, the polymerization proceeded at $323 \mathrm{~K}$ for $24 \mathrm{~h}$. The prepared hydrogels were sliced into flakes with the thickness of 3-4 $\mathrm{mm}$, and immersed in trichloromethane for $24 \mathrm{~h}$, in ethanol for $24 \mathrm{~h}$ and in deionized water for 7 days (replaced water every $8 \mathrm{~h}$ ) in succession to thoroughly leach out unreacted monomers and other unreacted ingredients. The dried hydrogels were obtained by vacuum drying under $323 \mathrm{~K}$ to constant weight.

2.2.4 Adsorption experiments. The batch adsorption experiments were conducted by adding the PNIPAM-TBCX xerogels into PCP solutions of different concentrations at 303 $\mathrm{K}$ for 24 hours shaking. All PCP solutions were obtained by dissolving PCP methanol solution in deionized water.

To evaluate the adsorption kinetic characteristics, $0.49 \mathrm{~g}$ PNIPAM-TBCX hydrogels were added in $300 \mathrm{~mL} 0.01 \mathrm{mmol} \mathrm{L}^{-1}$ PCP solution with magnetic stirring. At intervals, $1.0 \mathrm{~mL}$ PCP solution was withdrawn and analyzed via high performance liquid chromatography.

For the determination of the equilibrium adsorption isotherm, $10 \mathrm{mg}$ PNIPAM-TBCX hydrogels were added into $7 \mathrm{~mL}$ PCP solution of different concentrations and were shaken for $24 \mathrm{~h}$.

2.2.5 Desorption experiments. The adsorption-desorption process was used to investigate hydrogels' regeneration. The hydrogel saturated with PCP was immerged into a batch of deionized water for $24 \mathrm{~h}$ at $323 \mathrm{~K}$ to regenerate. The regenerated hydrogel was used for the next adsorption process, and the same adsorption-desorption procedure was performed in the succeeding cycles. 


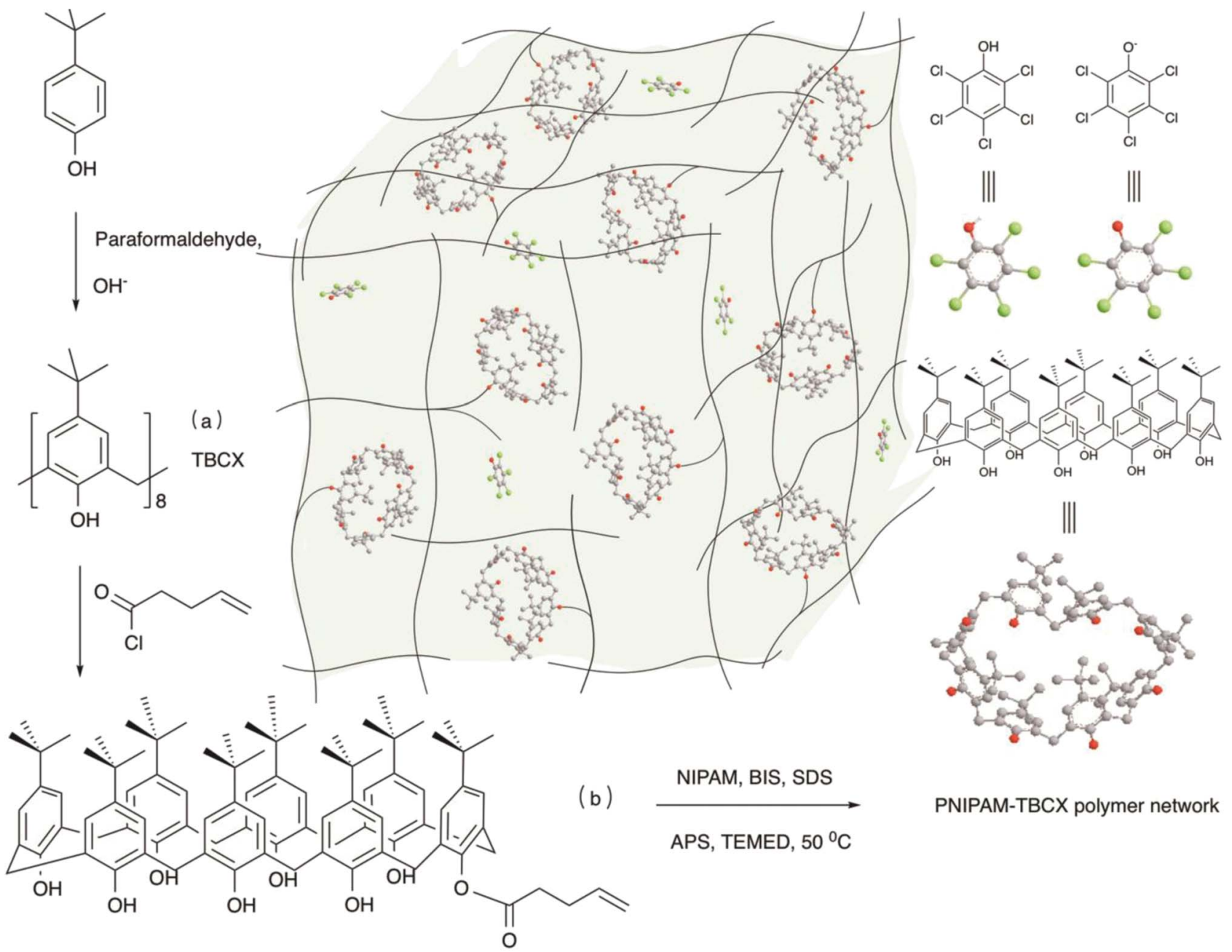

Fig. 1 Synthesis scheme of 4-tert-butylcalix[8]arene (a), O(1)-(4-pentenoyl)-p-tert-butylcalix[8]arene (b), PNIPAM-TBCX hydrogels and diagrammatic sketch of the PNIPAM-TBCX hydrogels in PCP aqueous solution.

\subsection{Analysis and characterization methods}

The concentration of PCP solution was detected by ultraviolet spectrometer (Shimadzu UV-1800) and high performance liquid chromatography (Shimadzu) using a chromatographic column (InertSustain C18) with a UV determine wavelength $220 \mathrm{~nm}$. The constituent of mobile phase was acetonitrile/water/acetic acid $=$ $75 / 25 / 1$. The functional groups of hydrogels were analyzed by the Fourier Transform Infrared Spectroscopy (FTIR, Bruker Tensor 27) with $\mathrm{KBr}$ pellet pressing method. ${ }^{1} \mathrm{H}$ and ${ }^{13} \mathrm{C}$ NMR spectra were recorded on a DRX-400 $\mathrm{MHz}$ (Bruker) nuclear magnetic resonance (NMR) spectrometer. The morphology of hydrogels was observed by FEI-quanta-200F scanning electron microscope. The BET surface area was detected by Micromeritics ASAP 2020.

The investigation of equilibrium swelling ratio (SR) was carried out under isothermal conditions ranging from 273 to $323 \mathrm{~K}$. The swelling equilibrium was reached by immerging hydrogels into deionized water until constant weight at different temperatures. The swelling ratio (SR) was calculated as $\mathrm{SR}=m_{\mathrm{h}} / m_{\mathrm{x}}$, where $m_{\mathrm{h}}$ and $m_{\mathrm{x}}$ represented the weight of hydrogel and xerogel, respectively.

\section{Results and discussion}

\subsection{Characterization}

The ${ }^{1} \mathrm{H}$ and ${ }^{13} \mathrm{C}$ NMR spectra of 4-tert-butylcalix[8]arene and $O(1)$ (4-pentenoyl)-p-tert-butylcalix[8]arene were shown in Fig. 2 and 3, respectively.

4-tert-Butylcalix[8]arene ${ }^{1} \mathrm{H}$ NMR (400 $\left.\mathrm{MHz}, \mathrm{CDCl}_{3}, \mathrm{ppm}\right)$ : $\delta 9.63(8 \mathrm{H}, \mathrm{s}, \mathrm{OH}), \delta 7.18(16 \mathrm{H}, \mathrm{s}, \mathrm{ArH}), \delta 4.38-4.35(8 \mathrm{H}, \mathrm{d}$, $\left.\mathrm{CH}_{2}(\mathrm{a})\right), \delta 3.52-3.43\left(8 \mathrm{H}, \mathrm{d}, \mathrm{CH}_{2}(\mathrm{~b})\right), \delta 1.25\left(72 \mathrm{H}, \mathrm{s}, \mathrm{CH}_{3}\right) \cdot{ }^{13} \mathrm{C}$ NMR (400 MHz, $\left.\mathrm{CDCl}_{3}, \mathrm{ppm}\right): \delta(31.5,32.3,125.5,128.7,144.7$, 146.6).

$O(1)-(4-P e n t e n o y l)-p$-tert-butylcalix[8]arene ${ }^{1} \mathrm{H} \quad \mathrm{NMR} \quad(400$ $\left.\mathrm{MHz}, \mathrm{CDCl}_{3}, \mathrm{ppm}\right): \delta 7.19(\mathrm{~s}, \mathrm{ArH}), \delta 5.82(\mathrm{~s}, \mathrm{CH}), \delta 5.08\left(\mathrm{CH}_{2}\right)$, $\delta 3.71\left(\mathrm{CH}_{2}\right), \delta 2.48\left(\mathrm{CH}_{2}\right), \delta 2.27\left(\mathrm{CH}_{2}\right), \delta 5.82(\mathrm{CH}), \delta 1.26\left(\mathrm{~s}, \mathrm{CH}_{3}\right)$. ${ }^{13} \mathrm{C}$ NMR (400 $\left.\mathrm{MHz}, \mathrm{CDCl}_{3}, \mathrm{ppm}\right): \delta(31.3,34.3,116.2,136.1$, 142.2, 148.3, 171.2).

Fig. 4 showed the FTIR spectra of PNIPAM-TBCX hydrogels. The carboxyl group stretching peak of ester appeared at $1659 \mathrm{~cm}^{-1}$, and the $\mathrm{C}-\mathrm{O}-\mathrm{C}$ of ester at $1180 \mathrm{~cm}^{-1}$. Both $3617 \mathrm{~cm}^{-1}$ and $719 \mathrm{~cm}^{-1}$ belonged to phenolic hydroxyl group, 


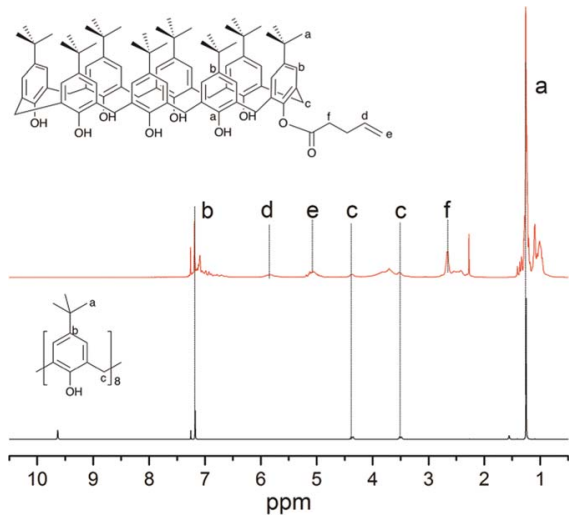

Fig. $2{ }^{1} \mathrm{H}$ NMR spectra of 4-tert-butylcalix[8]arene and O(1)-(4-pentenoyl)-p-tert-butylcalix[8]arene.

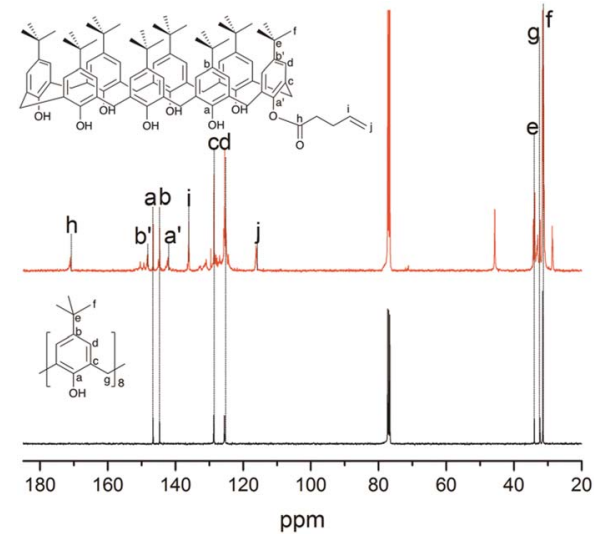

Fig. $3{ }^{13} \mathrm{C}$ NMR spectra of 4-tert-butylcalix[8]arene and $O(1)$-(4pentenoyl)-p-tert-butylcalix[8]arene.

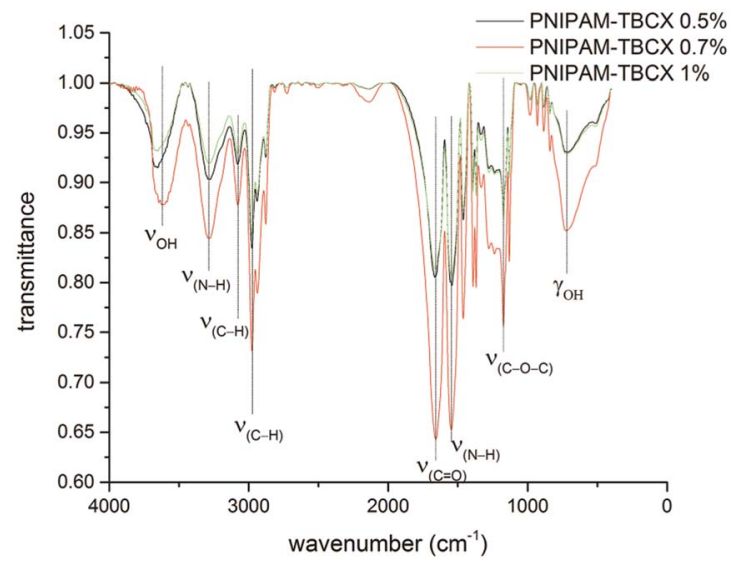

Fig. 4 Infrared spectra of the PNIPAM-TBCX hydrogels.

and $3077 \mathrm{~cm}^{-1}$ belonged to $\mathrm{C}-\mathrm{H}$ of calixarene. The PNIPAM segment showed the characteristic of $\mathrm{N}-\mathrm{H}$ stretching vibration at $3286 \mathrm{~cm}^{-1}, \mathrm{~N}-\mathrm{H}$ in-plane bending vibrations at $1545 \mathrm{~cm}^{-1}$ and $\mathrm{C}-\mathrm{H}$ stretching vibration at 2973, 2938 and $2878 \mathrm{~cm}^{-1}$. All

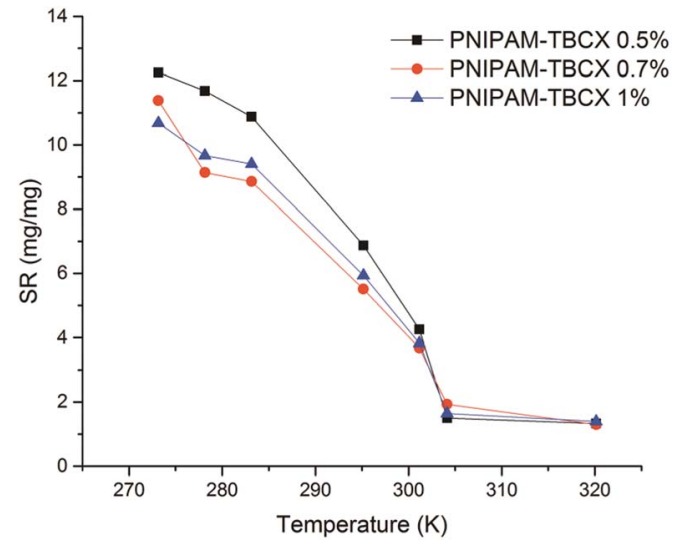

Fig. 5 Swelling ratios of different PNIPAM-TBCX hydrogels as a function of temperature. $\square$, PNIPAM-TBCX-0.5\% hydrogel; $\bullet$ PNIPAM-TBCX-0.7\% hydrogel; $\triangle$, PNIPAM-TBCX-1\% hydrogel.

the above data indicated that the PNIPAM-TBCX hydrogels were synthesized.

\subsection{Swelling ratios analysis}

Fig. 5 showed the temperature dependence of the swelling ratio (SR) for the PNIPAM-TBCX hydrogels. It could be seen that hydrogels with higher calixarene content exhibited lower SR. As the temperature rose, van der Waals' forces and hydrogen bonds between water and amide broke up, polymer chains shrank, and the hydrogels shrank macroscopically. At last, SR approached zero in the high temperature region. From $273 \mathrm{~K}$ to $320 \mathrm{~K}$, the SR of PNIPAM-TBCX-0.5\% hydrogel went down from 12.32 to only 1.33 . The SR curves had a sharp turn at $303 \mathrm{~K}$, which pointed that the LCST of PNIPAM-TBCX hydrogels was around $303 \mathrm{~K}$.

\subsection{Morphology and specific surface area analysis}

Fig. 6 showed the SEM results of the cryodesiccated PNIPAMTBCX hydrogels with different TBCX contents under 2000 and 500 magnifications. It could be seen that all the PNIPAM-TBCX hydrogels exhibited porous and net-shaped structures, and the pores and grids became lager with the increase of TBCX, which was consistent with the pore structure parameters of the PNIPAM-TBCX hydrogels, as showed in Table 1 . Within the PNIPAM-TBCX hydrogel, PNIPAM was cross-linked with TBCX which had rigid aromatic ring, providing larger porous and three-dimensional network structure with larger gap. However, too much calixarene contents would result in bad dispersing in the hydrogel, which would cause the porous structure of hydrogel to become agglomerated and inhomogeneous, as showed in the SEM images of PNIPAM-TBCX hydrogel-1\%.

\subsection{Effects of calixarene contents on the adsorption performance of hydrogels}

Fig. 7 showed the removal efficiencies of PCP adsorbed by the PNIPAM-TBCX hydrogels. Although PNIPAM-TBCX-1\% hydrogel had higher BET surface area and pore volume than PNIPAM- 

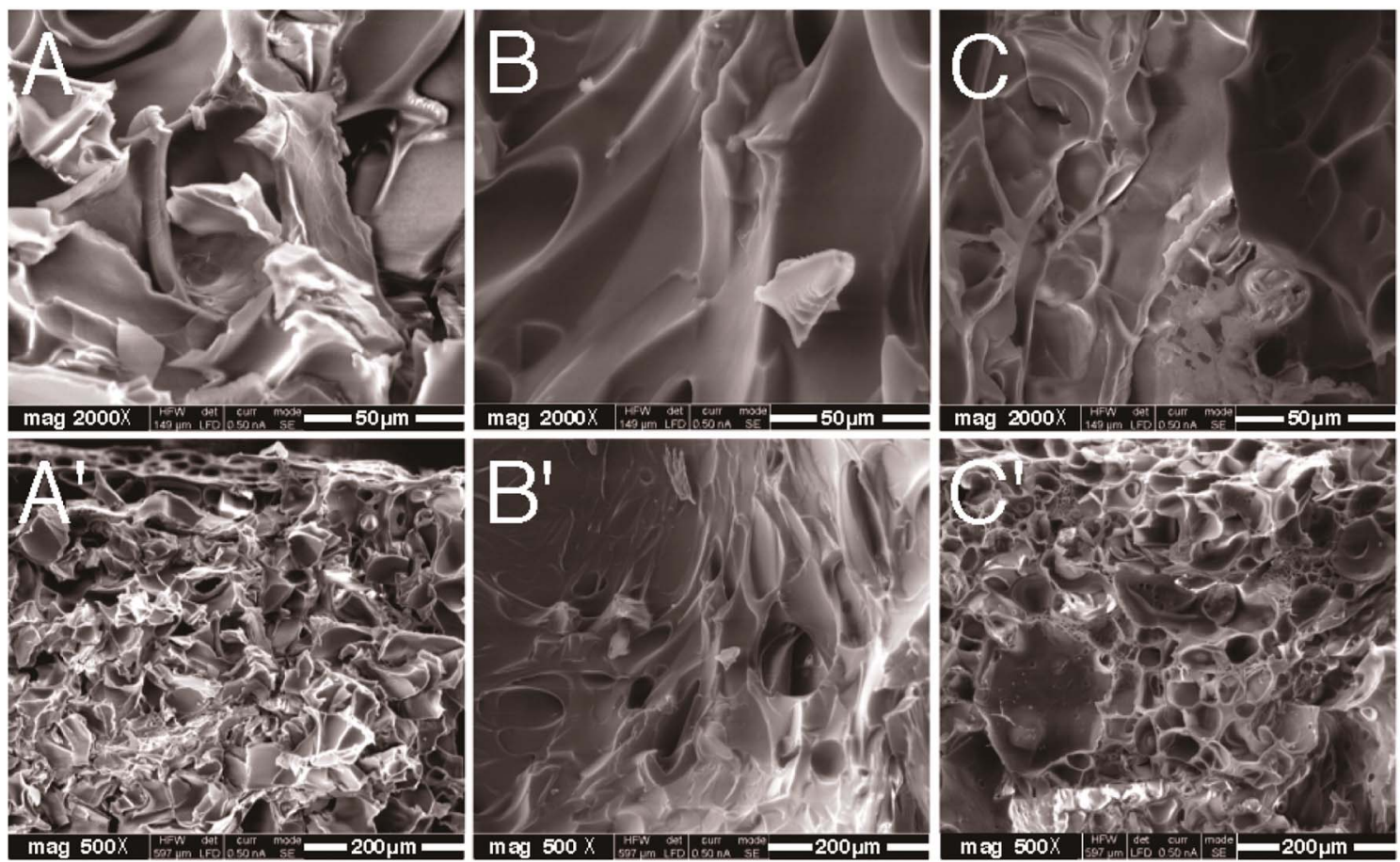

Fig. 6 SEM images of the PNIPAM-TBCX hydrogels. A, B, C are the SEM results of PNIPAM-TBCX-0.5\% hydrogel, PNIPAM-TBCX-0.7\% hydrogel, PNIPAM-TBCX-1\% hydrogel under 2000 magnifications, and $A^{\prime}, B^{\prime}, C^{\prime}$ are their SEM results under 500 magnifications.

Table 1 Surface area, pore volume and pore size of the PNIPAM-TBCX hydrogels

\begin{tabular}{lccc}
\hline & $\begin{array}{l}\text { BET surface } \\
\text { area }\left(\mathrm{m}^{2} \mathrm{~g}^{-1}\right)\end{array}$ & Pore volume $^{a}\left(\mathrm{~cm}^{3} \mathrm{~g}^{-1}\right)$ & Pore size $^{b}\left(\mathrm{~nm}^{-1}\right)$ \\
\hline PNIPAM-TBCX-0.5\% hydrogel & 17.8 & $6.28 \times 10^{-3}$ & 2.29 \\
PNIPAM-TBCX-0.7\% hydrogel & 5.16 & $5.88 \times 10^{-3}$ & 18.9 \\
PNIPAM-TBCX-1\% hydrogel & 28.2 & $2.69 \times 10^{-2}$ & 69.6
\end{tabular}

${ }^{a}$ Single point adsorption total pore volume of pores less than $433.68 \mathrm{~nm}$ diameter at $P / P_{0}=0.995-0.997$, where $P / P_{0}$ means the relative pressure of nitrogen gas's actual and saturation pressure. ${ }^{b} \mathrm{BJH}$ adsorption average pore diameter.

TBCX-0.7\% hydrogel, its removal efficiency of PCP was lower than that of PNIPAM-TBCX-0.7\% hydrogel. It was probably because that the conglomerations of TBCX in the PNIPAMTBCX hydrogel-1\% decreased the contact sites between TBCX and PCP, thereby affecting the interaction between them and reducing the removal efficiency of PCP. Compared with the TBCX- $0.7 \%$ hydrogel, the TBCX-0.5\% hydrogel had higher BET surface area and pore volume but lower removal efficiency of PCP. The possible reason was that the lower TBCX contents in the PNIPAM-TBCX-0.5\% hydrogel led to fewer binding sites of TBCX and PCP.

\subsection{Adsorption kinetics}

The adsorption kinetic experiments were performed to determine the equilibrium time of PCP adsorption by the PNIPAMTBCX hydrogels (Fig. 8). The removal rates of PCP by the PNIPAM-TBCX-0.5\% hydrogel and PNIPAM-TBCX-1\% hydrogel stayed almost constant after $600 \mathrm{~min}$, but the removal rate of PCP by the PNIPAM-TBCX-0.7\% hydrogel kept rising until
$800 \mathrm{~min}$. When the adsorptions reached equilibrium, the adsorption capacity of the PNIPAM-TBCX-0.7\% hydrogel was $2.08 \mathrm{mg} \mathrm{g}^{-1}$, which was higher than that of PNIPAM-TBCX-0.5\% hydrogel (1.96 $\mathrm{mg} \mathrm{g}^{-1}$ ) and PNIPAM-TBCX-1\% hydrogel $\left(2.02 \mathrm{mg} \mathrm{g}^{-1}\right)$. The adsorption capacity for PCP reached 1.52, 1.96 and $2.25 \mathrm{mg} \mathrm{g}^{-1}$ by poly( $N$-isopropylacrylamide-co-butyl acrylate) hydrogels at $\mathrm{pH}$ value of 3 in literature, ${ }^{\mathbf{1 7}}$ and the molar percentage ratios of butyl acrylate in the hydrogels were $0 \%, 5 \%$ and $11 \%$, respectively. Although the PNIPAM-TBCX hydrogels in this study had the similar adsorption capacity for PCP, their molar percentage ratios of TBCX were much lower, only $0.5 \%$, $0.7 \%$ and $1 \%$.

Pseudo-first-order ${ }^{32}$ and pseudo-second-order ${ }^{33}$ models were used to investigate the PNIPAM-TBCX hydrogel adsorption kinetics with eqn (1) and (2), respectively.

$$
\begin{gathered}
\ln \left(q_{\mathrm{e}}-q_{t}\right)=\ln q_{\mathrm{e}}-k_{1} t \\
\frac{t}{q_{t}}=\frac{1}{k_{2} q_{\mathrm{e}}{ }^{2}}+\frac{1}{q_{\mathrm{e}}} t
\end{gathered}
$$




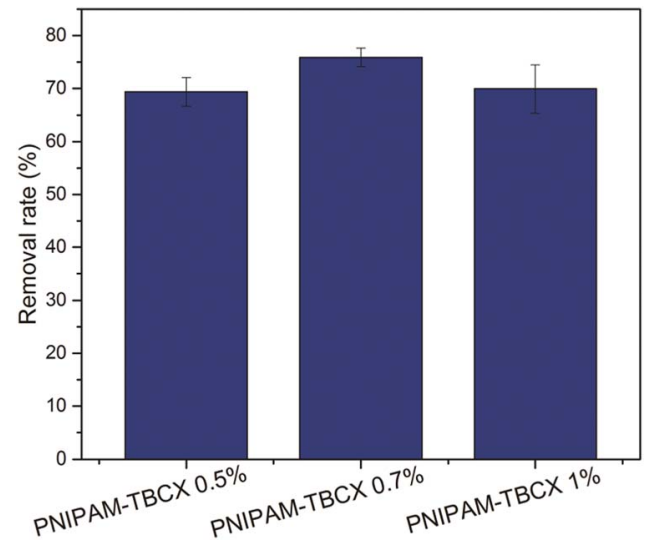

Fig. 7 Effects of TBCX contents on the removal of PCP by the PNIPAM-TBCX hydrogels.

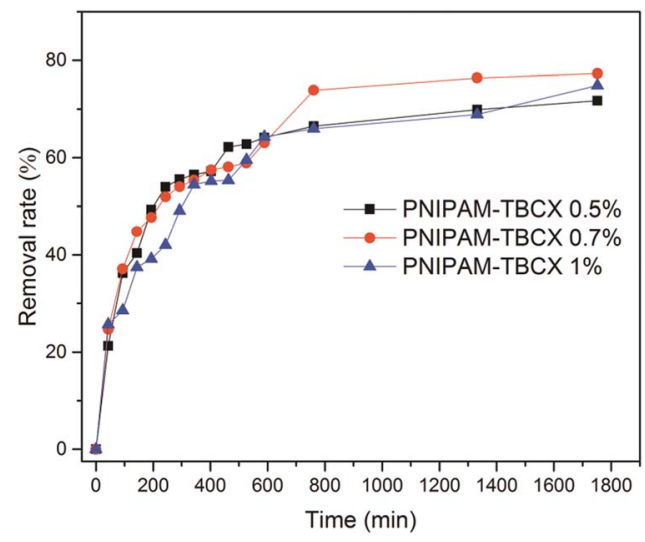

Fig. 8 Removal of PCP by PNIPAM-TBCX hydrogels with different TBCX contents against the adsorption time. $\square$, PNIPAM-TBCX-0.5\% hydrogel; $\bigcirc$, PNIPAM-TBCX-0.7\% hydrogel; $\boldsymbol{\Delta}$, PNIPAM-TBCX-1\% hydrogel.

where $q_{t}$ and $q_{\mathrm{e}}\left(\mathrm{mg} \mathrm{g}^{-1}\right)$ are the adsorption capacity at time $t$ and equilibrium, respectively, and $k_{1}(\mathrm{~min})$ and $k_{2}$ (g $\mathrm{mg}^{-1} \mathrm{~min}^{-1}$ ) are the pseudo-first-order and pseudo-secondorder rate constants, respectively.

From the values of $R^{2}$ fitted by pseudo-first-order and pseudo-second-order model in Table 2, we found that the adsorption kinetic data were fitted better by the pseudo-secondorder model than pseudo-first-order model. That $k_{2}$ increased in the order of PNIPAM-TBCX-0.5\% hydrogel > PNIPAM-TBCX$0.7 \%$ hydrogel $>$ PNIPAM-TBCX-1\% hydrogel, illustrated that the adsorption rate of PCP from solution onto the surface of PNIPAM-TBCX hydrogels decreased with the raising of TBCX content in the hydrogels. This may be because that higher TBCX content resulted in higher hydrophobicity of the surface of the hydrogels and lower diffusion rate of charged PCP species from the aqueous phase to the surface of the hydrogels. The value of $q_{\mathrm{e}}$ and $k_{2}$ indicated that although the adsorption rate increased with the decrease of TBCX content in the hydrogels, the adsorption capacity of PNIPAM-TBCX-0.7\% hydrogel was higher than PNIPAM-TBCX-0.5\% hydrogel and PNIPAM-TBCX-1\% hydrogel. Taking into account the fracture morphology of the PNIPAM-TBCX hydrogels, we speculated that in addition to the TBCX content, the porous structure of the hydrogels could also influence the adsorption capacity. Compact and uniform porous structure and higher TBCX contents both gave better adsorption capacity, but higher TBCX contents could result in agglomerated and inhomogeneous porous structure. Thus, it explained the highest adsorption capacity of PNIPAM-TBCX$0.7 \%$ hydrogel.

\subsection{Adsorption equilibrium isotherm of PCP removal}

Equilibrium isotherms were used to describe the experimental data of equilibrium adsorption (Fig. 9). It was seen that the adsorption capacity of the PNIPAM-TBCX-0.7\% hydrogel was higher than that of PNIPAM-TBCX-0.5\% hydrogel and PNIPAMTBCX-1\% hydrogel. When the PCP equilibrium concentration was $10.0 \mathrm{mg} \mathrm{L}^{-1}$, the adsorption capacities of PNIPAM-TBCX$0.5 \%$ hydrogel, PNIPAM-TBCX- $0.7 \%$ hydrogel and PNIPAM-

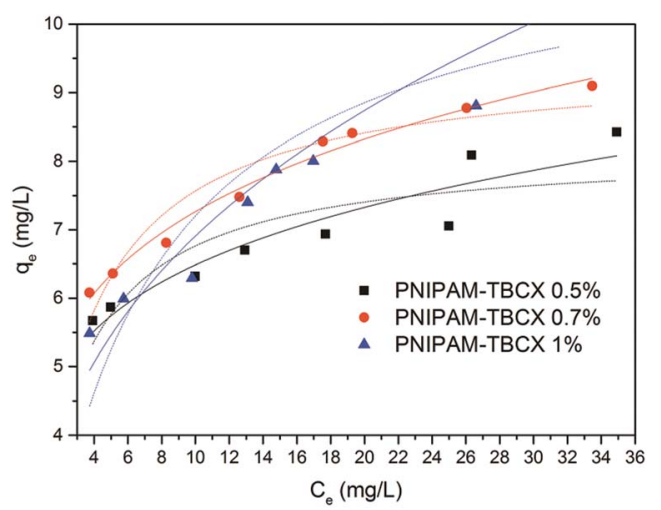

Fig. 9 Adsorption isotherm of PCP on the PNIPAM-TBCX hydrogels. 口. PNIPAM-TBCX hydrogel-0.5\%; •, PNIPAM-TBCX hydrogel-0.7\%; PNIPAM-TBCX hydrogel-1\%. The dashed line represented the Langmuir isotherm and the solid line represented the Freundlich isotherm.

Table 2 Pseudo-first-order and pseudo-second-order adsorption rate constants for adsorption of PCP on PNIPAM-TBCX hydrogels

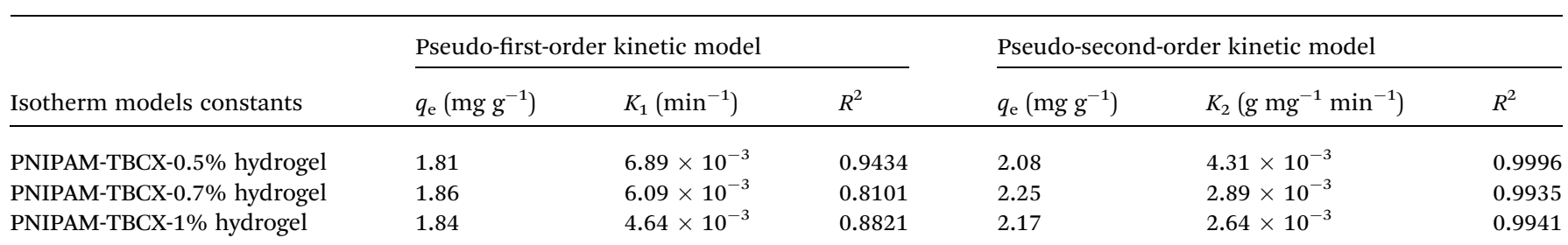


TBCX-1\% hydrogel were $6.49,7.27$ and $6.91 \mathrm{mg} \mathrm{g}^{-1}$, respectively. The results showed that the adsorption capacity of PNIPAM-TBCX hydrogel-0.7\% was 1.12 times of PNIPAM-TBCX hydrogel-0.5\% and 1.05 times of PNIPAM-TBCX hydrogel-1\%. This was probably because proper content of TBCX in the hydrogels could bind PCP, but excess TBCX led to the porous structure of the hydrogels agglomerated and inhomogeneous.

We used Langmuir and Freundlich isotherm model to fit the adsorption data. The Langmuir model was originally developed to represent chemisorption on a set of distinct localized adsorption sites, ${ }^{34}$ in which the homogeneity of the adsorbent is a prerequisite. The Langmuir isotherm ${ }^{35}$ can be represented as the following form (3):

$$
q_{\mathrm{e}}=\frac{q_{\mathrm{mon}} K_{\mathrm{L}} C_{\mathrm{e}}}{1+K_{\mathrm{L}} C_{\mathrm{e}}}
$$

$c_{\mathrm{e}}$ is the equilibrium PCP concentration $\left(\mathrm{mg} \mathrm{L}^{-1}\right), q_{\mathrm{e}}$ is the saturated adsorbance $\left(\mathrm{mg} \mathrm{g}^{-1}\right), K_{\mathrm{L}}$ is the Langmuir constant related to the adsorption energy, $q_{\text {mon }}$ is the Langmuir constant related to the adsorption capacity and the amount of adsorbate at monolayer coverage.

The empirical isotherm, Freundlich equation can be represented as the following form (4):

$$
q_{\mathrm{e}}=K_{\mathrm{f}} C_{\mathrm{e}^{n}}^{\frac{1}{n}}
$$

where $K_{\mathrm{f}}$ and $1 / n$ are Freundlich constants in relation to adsorption capacity and energy distribution of the adsorption sites, respectively.

The parameter values of the Langmuir and Freundlich isotherm model were shown in Table 3 . The equilibrium adsorption data of PCP on different PNIPAM-TBCX hydrogels were fitted to Freundlich isotherm model better than Langmuir isotherm model. And $r_{\mathrm{L}}^{2}$ value of the Langmuir equation was lower than 0.99, indicating the inhomogeneous nature of the PNIPAM-TBCX hydrogels, and was consistent with SEM results.

The essential features of Langmuir adsorption isotherm can be expressed in terms of a dimensionless constant called separation factor or equilibrium parameter $\left(R_{\mathrm{L}}\right),{ }^{36}$ which is defined by the following relationship (5):

$$
R_{\mathrm{L}}=\frac{1}{1+K_{\mathrm{L}} C_{0}}
$$

where $C_{0}$ is the initial dye concentration $\left(\mathrm{mg} \mathrm{L}^{-1}\right)$. The $R_{\mathrm{L}}$ value indicates the shape of the isotherm to be irreversible $\left(R_{\mathrm{L}}=0\right)$, favorable $\left(0<R_{\mathrm{L}}<1\right)$, linear $\left(R_{\mathrm{L}}=0\right)$ or unfavorable $\left(R_{\mathrm{L}}>1\right)$. By dealing with the eqn (3), the $R_{\mathrm{L}}$ values were amongst the favorable range in all processes $\left(0<R_{\mathrm{L}}<1\right)$. The PNIPAM-TBCX$0.7 \%$ hydrogel had higher value of $r_{\mathrm{L}}{ }^{2}$ than the other two hydrogels, which probably indicated that there were more TBCX-PCP complexes formed on its surface. This might be because the PNIPAM-TBCX-0.7\% hydrogel had higher content of TBCX than the PNIPAM-TBCX-0.5\% hydrogel, and exhibited the more homogeneous phase structure than the PNIPAMTBCX-1\% hydrogel.

In consideration of the inhomogeneous phase structure of the PNIPAM-TBCX hydrogels, it was supposed that the adsorption of PCP on the hydrogels was multilayer. Referring to multilayer adsorption isotherm of gas adsorbed on solid, ${ }^{37}$ it was speculated that the multilayer adsorption isotherm of adsorbate or solute adsorbed on the adsorbent from solution could expressed in the following eqn (6), based on the assumption that the competitive adsorption of solvent on the adsorbent relative to could be ignored. The adsorption data were fitted in Fig. 10.

$$
q_{\mathrm{e}}=\frac{k q_{\mathrm{mon}} c_{\mathrm{e}}}{\left(c_{\max }-c_{\mathrm{e}}\right)\left[1+\frac{(k-1) c_{\mathrm{e}}}{c_{\max }}\right]}
$$

where $c_{\mathrm{e}}, k, q_{\text {mon }}$ and $c_{\text {max }}$ was the equilibrium PCP concentration $\left(\mathrm{mg} \mathrm{L}^{-1}\right)$, the ratio of the adsorption time of the adsorbate directly bounded to the surface of the adsorbent to the

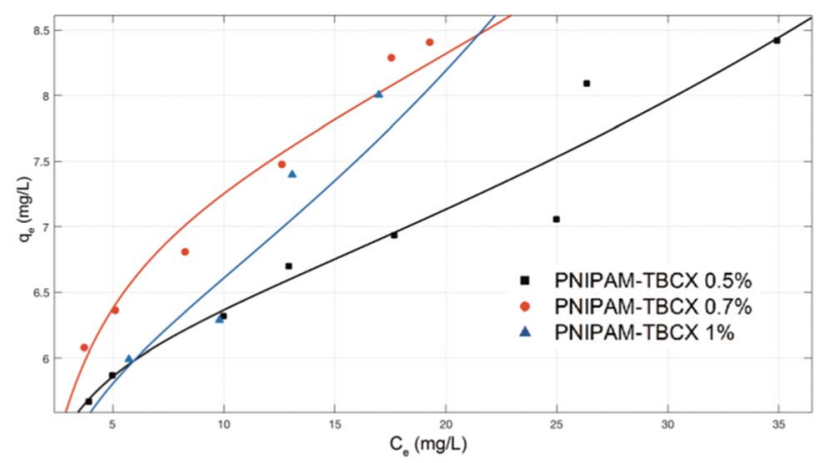

Fig. 10 The multilayer adsorption isotherm of PCP on the PNIPAM-

\begin{tabular}{|c|c|c|c|c|}
\hline \multirow[b]{2}{*}{ Isotherm models } & \multirow[b]{2}{*}{ Constants } & \multicolumn{3}{|l|}{ Absorbents } \\
\hline & & PNIPAM-TBCX-0.5\% & PNIPAM-TBCX-0.7\% & PNIPAM-TBCX-1\% \\
\hline \multirow[t]{4}{*}{ Langmuir } & $q_{\mathrm{mon}}\left(\mathrm{mg} \mathrm{g}^{-1}\right)$ & 8.18 & 9.47 & 11.5 \\
\hline & $K_{\mathrm{L}}\left(\mathrm{L} \mathrm{mg}^{-1}\right)$ & 0.477 & 0.399 & 0.168 \\
\hline & $R_{\mathrm{L}}$ & $0.0566-0.349$ & $0.0698-0.402$ & $0.159-0.615$ \\
\hline & $r_{\mathrm{L}}^{2}$ & 0.7246 & 0.9162 & 0.732 \\
\hline \multirow[t]{3}{*}{ Freundlich } & $K_{\mathrm{F}}\left(\mathrm{mg}^{1-1 / n} \mathrm{~kg}^{1 / n} \mathrm{~g}^{-1}\right)$ & 4.32 & 4.62 & 3.16 \\
\hline & $1 / n\left(\mathrm{~kg} \mathrm{~g}^{-1}\right)$ & 0.176 & 0.196 & 0.340 \\
\hline & $r_{\mathrm{F}}^{2}$ & 0.8729 & 0.9842 & 0.8722 \\
\hline
\end{tabular}
TBCX hydrogels. $\mathbf{\square}$, PNIPAM-TBCX hydrogel-0.5\%; $\bullet$ PNIPAM-TBCX hydrogel-0.7\%; $\boldsymbol{\Delta}$, PNIPAM-TBCX hydrogel-1\%.

Table 3 Langmuir and Freundlich constants for adsorption of PCP on the PNIPAM-TBCX hydrogels 
Table 4 The constants of the derived function $q_{\mathrm{e}}=k q_{\operatorname{mon}} c_{\mathrm{e}} /\left[\left(c_{\max }-\right.\right.$ $\left.\left.c_{\mathrm{e}}\right)\left(1+(k-1) c_{\mathrm{e}} / c_{\text {max }}\right)\right]$ fitted by matlab for adsorption of PCP on PNIPAM-TBCX hydrogels

\begin{tabular}{lllc}
\hline & Absorbents & & \\
\cline { 2 - 4 } & $\begin{array}{l}\text { PNIPAM- } \\
\text { TBCX-0.5\% }\end{array}$ & $\begin{array}{l}\text { PNIPAM- } \\
\text { TBCX-0.7\% }\end{array}$ & $\begin{array}{l}\text { PNIPAM- } \\
\text { TBCX-1\% }\end{array}$ \\
\hline$q_{\mathrm{mon}}$ & 6.061 & 7.275 & 5.867 \\
$\left(\mathrm{mg} \mathrm{g}^{-1}\right)$ & 295 & 126.9 & 136.9 \\
$k$ & 121.4 & 124.7 & 67.57 \\
$c_{\max }$ & & & 0.9353 \\
$r^{2}$ & 0.9079 & 0.9658 &
\end{tabular}

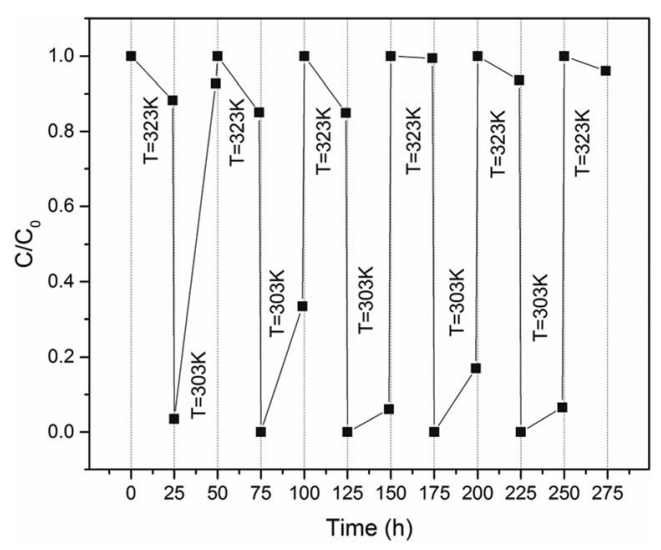

Fig. 11 Adsorption/desorption circulation behavior of PCP as a function of time and temperature.

adsorption time of the adsorbate adsorbed to the first layer, the adsorption amount of unit mass $\left(\mathrm{mg} \mathrm{g}^{-1}\right)$ when a single molecular layer was formed, the minimum concentration of the solution at the time of saturated adsorption, respectively.

The parameter values of the multilayer adsorption equation for solution were shown in Table 4. The equilibrium adsorption data of PCP on different PNIPAM-TBCX hydrogels were fitted to the multilayer adsorption equation better than Langmuir isotherm model, which indicated that the PCP adsorption on the hydrogels probably included chemisorption and multilayer adsorption. The values of $q_{\text {mon }}$ fitted by the multilayer adsorption equation were lower than that from Langmuir isotherm model, which further strengthened the above point of view. In addition, from the values of $k$, it could be seen that the adsorption time of the adsorbate directly bounded to the surface of the adsorbent was the two orders of magnitude larger than that of the adsorbate adsorbed to the first layer, which indicated that the first layer adsorption belonged to chemical adsorption and played a major role.

\subsection{The reusability of hydrogels}

The reusable experiments of PNIPAM-TBCX hydrogels were performed in aqueous solution. The hydrogels were immersed in PCP aqueous to adsorb PCP until equilibrium at $303 \mathrm{~K}$ for
$24 \mathrm{~h}$, immerged into deionized water at 320-323 $\mathrm{K}$ for another $24 \mathrm{~h}$ to desorb PCP. The adsorption-desorption cycle was repeated several times. The results were illustrated in Fig. 11. The regeneration rate of the PNIPAM-TBCX- $0.7 \%$ hydrogels was still $95 \%$ after five circles. The results indicated that the PNIPAM hydrogels modified by 4-tert-butylcalix[8]arene had reversible adsorption-desorption of PCP by adjusting temperature.

PCP desorption from PNIPAM-TBCX hydrogels at temperature over LCST was probably related to several factors. When the temperature surpassed the LCST, the delicate hydrophilic/ hydrophobic balance in the network structure was disrupted, so the hydrogel dehydrated and shrank. As the hydrogel shrank, exposed surface decreased, thus resulting in the decrease of adsorptive sites. TBCX and NIPAM compacted together and weakened the interaction between themselves. Moreover, higher temperature led to higher solubility of PCP in aqueous solution. Thus, the regeneration of PNIPAM-TBCX hydrogels could be easily achieved by changing the solution temperature.

\section{Conclusions}

We synthesized the thermal-sensitive PNIPAM-TBCX hydrogels via aqueous micellar polymerization. The TBCX modified PNIPAM-TBCX hydrogels exhibited considerable adsorption capacity for PCP in neutral aqueous solutions. The parameter values fitted by Langmuir, Freundlich and the derived multilayer adsorption equation indicated inhomogeneous nature of the hydrogels and the mixed chemical and multilayer adsorption of PCP. After several cycles of adsorption and desorption, the regeneration rates of the PNIPAM-TBCX- $0.5 \%$ and PNIPAMTBCX- $0.7 \%$ hydrogels were still over $80 \%$. Accordingly, the PNIPAM-TBCX hydrogels could be a highly efficient and easily regenerated adsorbent to remove pollutant in wastewater.

\section{Conflicts of interest}

There are no conflicts to declare.

\section{Acknowledgements}

We appreciated the financial support to this study by the Guangdong Academy of Sciences Project (No. 2017GDASCX0705).

\section{References}

1 G. Kovacevic and A. Sabljic, Chemosphere, 2016, 159, 488495.

2 L. L. Miller, L. D. Ingerman and M. Singh, Toxicological Profile for Pentachlorophenol, 2001.

3 K. Hlouchova, J. Rudolph, J. M. Pietari, L. S. Behlen and S. D. Copley, Biochemistry, 2012, 51, 3848-3860.

4 R. Szewczyk, P. Bernat, K. Milczarek and J. Dlugoński, Biodegradation, 2003, 14, 1-8.

5 E. Y. Kim, Y. J. Choi, H. J. Chae and K. H. Chu, Biotechnol. Bioprocess Eng., 2006, 11, 462-465. 
6 D. P. Ho, M. Senthilnanthan, J. A. Mohammad, S. Vigneswaran, H. H. Ngo, G. Mahinthakumar and J. Kandasamy, J. Adv. Oxid. Technol., 2010, 13, 21.

7 J.-Y. Huang, W.-P. Liao and S.-M. Lai, Environ. Earth Sci., 2013, 68, 2281-2288.

8 R. Cheng, C. Cheng, P. Liu, L. Shi and Z. Ma, Water Sci. Technol.: Water Supply, 2016, 16, 810.

9 K. Kuśmierek, P. Idźkiewicz, A. Świątkowski and L. Dąbek, Arch. Environ. Prot., 2017, 43, 10-16.

10 N. T. Abdel-Ghani, G. A. El-Chaghaby and E. M. Zahran, Int. J. Environ. Sci. Technol., 2015, 12, 211-222.

11 P. Peng, Y.-H. Lang and X.-M. Wang, Ecol. Eng., 2016, 90, 225-233.

12 R. X. Wang, D. J. Zhang, R. X. Zhu and C. B. Liu, J. Mol. Model., 2014, 20, 2093.

13 M. Abdel Salam and R. C. Burk, Water, Air, Soil Pollut., 2010, 210, 101-111.

14 M. Y. Nassar and M. Khatab, RSC Adv., 2016, 6, 79688-79705.

15 Y. K. Penke, G. Anantharaman, J. Ramkumar and K. K. Kar, RSC Adv., 2016, 6, 55608-55617.

16 K. M. Pang, S. Ng, W. K. Chung and P. K. Wong, Water, Air, Soil Pollut., 2007, 183, 355-365.

17 B. Yang, D. Xu, X. Wu, Z. Li, L. Lei and X. Zhang, J. Ind. Eng. Chem., 2015, 25, 67-72.

18 G. Huerta-Angeles, K. Hishchak, A. Strachota, B. Strachota, M. Šlouf and L. Matějka, Eur. Polym. J., 2014, 59, 341-352.

19 S. Lv, L. Liu and W. Yang, Langmuir, 2010, 26, 2076-2082.

20 X.-Y. Zhang, Y. Zheng, C.-H. Liu, P.-H. Wang and Y.-Y. Zhu, RSC Adv., 2016, 6, 55666-55670.
21 X.-J. Ju, S.-B. Zhang, M.-Y. Zhou, R. Xie, L. Yang and L.-Y. Chu, J. Hazard. Mater., 2009, 167, 114-118.

22 S. Ashraf, H.-K. Park, H. Park and S.-H. Lee, Macromol. Res., 2016, 24, 297-304.

23 C. D. Gutsche, Calixarenes: An Introduction, 2008.

24 C. D. Gutsche, Calixarenes Revisited, 1998.

25 L. Yang, X. Ran, L. Cai, Y. Li, H. Zhao and C. P. Li, Biosens. Bioelectron., 2016, 83, 347-352.

26 B. Lotfi, A. Tarlani, P. Akbari-Moghaddam, M. MirzaAghayan, A. A. Peyghan, J. Muzart and R. Zadmard, Biosens. Bioelectron., 2017, 90, 290-297.

27 F. Yan, M. Wang, D. Cao, S. Guo and L. Chen, J. Polym. Sci., Part A: Polym. Chem., 2013, 51, 2401-2408.

28 R. Marouf, N. Khelifa, K. Marouf-Khelifa, J. Schott and A. Khelifa, J. Colloid Interface Sci., 2006, 297, 45-53.

29 J. H. Munch and C. D. Gutsche, Org. Synth., 1990, 68, 243246.

30 R. J. Kazlauskas, Org. Synth., 1992, 70, 60-65.

31 G. Chen, A synthetic method of 3,4-dihydro-7-hydroxy-2(1H)quinolinone, CN 105017146A, 2015.

32 D. K. Chattoraj and D. Sarkar, J. Colloid Interface Sci., 1993, 157, 219-226.

33 G. M. Y. S. Ho, J. Environ. Sci. Health Part. A-Toxic/Hazard. Subst. Environ. Eng., 1999, 34, 1179-1204.

34 D. M. Ruthven, Principles of Adsorption and adsorption processes, Wiley, 1984, p. 49.

35 I. Langmuir, J. Am. Chem. Soc., 1915, 37, 1139-1167.

36 P. K. Malik, J. Hazard. Mater., 2004, 113, 81-88.

37 J. H. d. Boer, Kinetic Characteristics of Adsorption, Science Press, 1964, p. 59. 